\title{
Personnel training for the developing nuclear power industry
}

\author{
Alexandr V. Putilov ${ }^{1}$, Mikhail N. Strikhanov ${ }^{1}$, Georgy V. Tikhomirov ${ }^{1}$ \\ 1 National Research Nuclear University MEPhI, 31 Kashirskoe shosse, Moscow, 115409 Russian Federation \\ Corresponding author: Georgy V.Tikhomirov (gvtikhomirov@mephi.ru)
}

Academic editor: Yury Korovin • Received 27 May 2019 • Accepted 15 August 2019 Published 25 September 2019

Citation: Putilov AV, Strikhanov MN, Tikhomirov GV (2019) Personnel training for the developing nuclear power industry. Nuclear Energy and Technology 5(3): 201-206. https://doi.org/10.3897/nucet.5.39239

\begin{abstract}
The article briefly describes the history of training personnel for the nuclear industry and sets tasks for its improvement and development to ensure the future growth of this industry. Within the framework of the emerging digital economy, such a phenomenon as digital platforms erases the boundaries between industries, forming new unexpected industrial alliances, even new industries. Innovative activities in the power industry, including nuclear power, should provide the possibility of forming digital economic platforms in various energy segments as well as training personnel in using this new toolkit. Today, the Rosatom State Nuclear Energy Corporation is developing more than 30 projects of new nuclear power plants (NPP) in Russia and 12 other countries. This requires educational support, and for this purpose a Consortium of supporting universities of the Rosatom State Corporation was established, which includes 18 specialized higher educational institutions. More than half of them train personnel directly for designing, constructing and operating NPPs. The scale of the necessary personnel training in the near future indicates that we need a new "educational paradigm", which can be described as "front-line education", i.e., training personnel for developing digital economy technologies simultaneously along the entire "front". This "front" stretches from schoolchildren preparing to enter universities to production personnel whose professional development should be carried out taking into account the specifics of the digital transformation of production. Partnership is one of the leading values of the modern young generation. To withstand high competition for the best personnel, organizations must not only be saturated with the culture of partnership from the inside but also act as reliable partners for one another in involving and training young employees.
\end{abstract}

\section{Keywords}

Nuclear power, educational technology, digital economy in the nuclear industry, personnel development, export of education

\section{Introduction}

Training personnel for the economy of the future is one of the key problems of the world community today. According to the International Organization for Economic Cooperation and Development (OECD), more than 30\% of workers in the world now do not meet the requirements of employers, and this gap continues to grow. Experts state that the global economy today receives less than two trillion dollars of world income due to a shortage of professional personnel. The transformation of global labor markets and the employment institution, the pace and complexity of technological and social changes require adequate solutions and a revision of the principles of international

* Russian text published: Izvestiya vuzov. Yadernaya Energetika (ISSN 0204-3327), 2019, n. 2, pp. 208-218.

Copyright Putilov AV et al. This is an open access article distributed under the terms of the Creative Commons Attribution License (CC.BY 4.0), which permits unrestricted use, distribution, and reproduction in any medium, provided the original author and source are credited. 
cooperation. For the nuclear industry, which is the driver for developing high technologies in our country, the personnel problem is becoming one of the main ones.

\section{Historical review of personnel training for the nuclear industry}

The Moscow Mechanical Institute of Munitions (the predecessor of NRNU MEPhI) as early as in 1945 began training specialists of a new type, capable of not only conducting scientific research but also bringing scientific developments to practical use. In September 1945, a decision was made to create a new engineering and physics faculty, the main organizer and first dean of which was Alexandr Ilyich Leipunsky, an outstanding specialist in the field of nuclear physics, who at the same time headed the leading department of the faculty, i.e., "Applied Nuclear Physics" (Kirillov 2018). Leading physicists were involved in teaching at the new faculty, e.g., academicians I.Ye. Tamm, L.A. Artsimovich, M.A. Leontovich, I.Ya. Pomeranchuk, I.K. Kikoin and many others. Six Russian Nobel Prize laureates took part in the formation and development of MEPhI at various time periods, the alley of their sculptural portraits was opened on the university campus and is constantly updated.

In the spring of 1946, regular classes began in the framework of the new faculty, and in the late 1940s - early 1950s graduates of the new faculty - physics engineers of the new formation - came to the domestic nuclear industry. Subsequently, many of them became leading specialists and then heads of institutes and enterprises of the USSR Ministry of Medium Machine-Building Industry, the Ministry of Atomic Energy of Russia, and Rosatom. This "educational leap" was due to the implementation of the four principles of engineering and physical education formulated by A.I. Leipunsky and remaining relevant to this day:

- serious fundamental training in physics, mathematics and engineering;

- involvement in teaching of scientists and specialists directly working in the nuclear industry and having sufficient practical experience;

- establishment of departments or laboratories on the latest problems of science and technology, fitted with modern equipment; and

- special selection of applicants and students who could independently cope with the upcoming work.

All these principles are still relevant, the format for their implementation has changed, but the goals have remained the same, i.e., training of highly efficient personnel for developing the nuclear industry. This year marks the $65^{\text {th }}$ anniversary of the launch of the world's first nuclear power plant in Obninsk. It should be noted that personnel for this first-born of the nuclear industry and other
NPPs for many years was prepared at the INPE NRNU MEPhI in Obninsk. Today the "Obninsk site" of our university is a developing center of both atomic science and modern education. The joint creative efforts of specialists in Moscow and Obninsk yields positive results - new educational formats, material and technical resources and high professionalism of the teaching staff provide the opportunity to establish large-scale export of nuclear education to many countries of the world.

\section{The nuclear industry of Russia as a locomotive moving to a modern digital economy}

The economy has long been described in visual images of the railway, i.e., economic rails, locomotive companies, trunk lines, etc. Today, a new phenomenon has been added to this railway allegory and it threatens to restructure not only the timetable for success in the economy and business but also to redraw the entire landscape of the modern market as we used to know it. We are talking about digital platforms - they blur the boundaries between industries and form new unexpected industrial alliances, even new industries. Innovative activities in the energy sector, including nuclear energy (Ivanov and Putilov 2017, Putilov et al. 2010), should provide the opportunity to form digital economic platforms in various energy segments. Training personnel for developing and implementing digital platforms is an urgent task for the near future. Over the last few years, NRNU MEPhI together with Atomstroyexport - ASE Group of Companies have successfully mastered a new training format, i.e., developing specialist competences for creating domestic design NPPs abroad, which was designated as developing the Multy-D system (three-dimensional digital model of the future NPP and additional dimensions in the format of terms, resources, etc.). Multi-D makes it possible to some extent to simulate the life cycle of a particular nuclear power plant; however, the transition to new technological principles requires changes in modeling systems. For example, the creation of a closed nuclear fuel cycle with fast neutron reactors (the "Proryv" [Breakthrough] project) requires taking into account not only new types of reactor facilities but also new nuclear fuel, its production and processing. These problems are currently being studied at a department specially created at NRNU MEPhI; many teachers are experts on the Proryv project.

In fact, the digital platform is a new business model based entirely on high technology that provides profit-making through effective information exchange between two or more independent groups of participants who create and use goods and services. In the "basic configuration", digital platforms directly bring together manufacturers and end users, who are able to interact without intermediaries. They also enable various companies to share information in a special way and, as a result of this 
exchange, significantly improve cooperation and create innovative products and solutions. State corporations (Ilyina and Putilov 2012) in our country (primarily the Rosatom State Corporation) are a kind of "locomotives" in certain areas of high-tech growth (nuclear energy, space, defense industry, etc.). The transition to a qualitatively new information format for economic relations will require a significant organizational restructuring from the production structure, which will optimize the management system and increase economic efficiency. For this restructuring, it is necessary to prepare personnel of a new type, using a kind of symbiosis of engineering, information and economic training. Digital platforms make profit increase in proportion to the number of participants; therefore, access to the global high-tech markets (nuclear power certainly belongs to this type of technology) is our most urgent task, and training foreign citizens along with domestic youth is a reliable tool for subsequent international technological expansion. Exporting education is a way of promoting global technology markets.

\section{World nuclear market and export of education}

Today, the State Atomic Energy Corporation Rosatom is developing more than 30 projects of new nuclear power plants in Russia and 12 other countries. This requires educational support, and for this purpose a Consortium of supporting universities of the Rosatom State Corporation (hereinafter referred to as the Consortium) was established. The Consortium includes 18 specialized universities. More than half of them train personnel directly for designing, constructing and operating NPPs. The basic university of the Rosatom State Corporation is NRNU MEPhI, which has an extensive network of branches in the cities hosting nuclear industry organizations, some of which train specialists for the nuclear industry. The university unites 11 higher educational institutions and six vocational schools located in 17 cities of 13 constituent entities of the Russian Federation (including nine Rosatom Closed Cities and many other "nuclear" cities). Today NRNU MEPhI counts about 25 thousand students (including more than 1,500 foreign citizens from more than 50 countries) and more than 2,000 teachers, including hundreds of doctors and candidates of science, more than 1,000 graduate and doctoral students. Personnel training is carried out in 60 specialties and areas of higher education and 45 specialties of secondary vocational education, most of them are widely sought after by organizations of the nuclear industry. The University has more than 10 educational research centers for collective use, more than 50 research centers with leading enterprises and research organizations of the nuclear industry, the Russian Academy of Sciences, state corporations and companies. Capital investments are being made in the University infrastructure (the construction of new educational buildings, expansion of the hostel fund, etc.). The efforts being made bring noticeable results, i.e., NRNU MEPhI is included in the ratings of 300 best universities in the world according to the Times Higher Education (Great Britain) and 100 leading universities of Russia according to the Expert RA agency. Following the meeting of the Council on improving the competitiveness of leading universities of the Russian Federation among the world's leading scientific and educational centers (Project Council 5-100), chaired by the Deputy Prime Minister of the Russian Federation O.Yu. Golodets, National Research Nuclear University MEPhI was ranked among the leaders in the implementation of competitiveness improvement programs, whose work was rated more than seven points. In order to bring as many graduates with high potential as possible to the nuclear industry, a program is being implemented to expand the place of practical training in organizations of the nuclear industry. For example, in 2018, more than 5,800 university students completed practical training; more than 1,200 graduates were employed in the nuclear industry (almost half were from the supporting universities). To facilitate the acquaintance of students and graduates with the enterprises of the nuclear industry, the Rosatom State Corporation annually holds Rosatom Career Days at NRNU $\mathrm{MEPhI}$ and its affiliates, and other supporting universities of the state corporation. These events have become a traditional meeting place for the most active students with representatives of nuclear industry organizations. Here, students and graduates are given unique opportunities to find interesting and promising jobs.

In addition, the Rosatom Career Center operating at NRNU MEPhI on an ongoing basis, provides advice for students on employment in the nuclear industry. Specialists of the Center help students find out what enterprises they may be in demand at. Each year, a reference book for students, "Careers in the Nuclear Industry", is published, which, in addition to general information on the development of nuclear energy, contains a catalog of nuclear industry enterprises with information about specialists and specialties they need. The Center also organizes events for students with the participation of nuclear industry employers, i.e., meetings of students and employers, conferences, presentations, lectures, seminars, trainings, business games, and round tables.

\section{Developing leading research centers and the problem of personnel training}

The program "Digital Economy of the Russian Federation" is being implemented in our country, however, the digital economy develops as a positive phenomenon only when new end-to-end digital technologies (EDT) change business schemes for production, consumption, distribution and exchange, due to which an economic effect arises and new economic relations are formed. For the Rosatom 
State Corporation, this approach is most important, because unlike a number of other industries (for example, quantum technologies at the present stage of development can be justified for creating single fundamentally new designs), mass production of high-tech products in the nuclear industry is one of four main components of the real economy sector. When forming roadmaps for the development of the EDTs in the digital economy, for which the Rosatom State Corporation took responsibility in the spring of 2019 and became the customer of all nine roadmap projects, it is important that the possibility of a noticeable economic effect be "sewn" into the set of measures with timelines and amount of financing. Forecasting the development of "economic fronts" is developed as a system of models, analysis and processing of big data, the use of the results of such modeling allows us to draw a number of conclusions for the development of educational practice.

The program "Digital Economy of the Russian Federation" and road mapping technologies, based on which the Rosatom State Corporation develops its activities, provides for the concept of leading research centers (LRCs) created to further work on individual end-to-end digital technologies, and in some cases, for individual specific sub-technologies. For the majority of digital technologies used in mass production, it is advisable to transform the concept of LRCs, i.e., a leading research center should become a scientific and educational complex. Rosenergoatom also adopted a digital nuclear energy development strategy, and plans are being drawn up for the large-scale use of end-to-end digital technologies. Only based on large-scale training, new research and digital production technologies will be able to provide a sufficient economic effect. Expert estimates show that for almost every sub-technology (within the framework of end-to-end digital technologies), with its large-scale implementation, several thousand specialists (developers, programmers, testers, operators, business managers, etc.) will need to be trained over the next few years, which, at the domestic level, is one of the main tasks to be solved in the proposed centers.

The scale of the necessary personnel training in the near future indicates that we need a new "educational paradigm", which can be described as "front-line education", i.e., training personnel for developing digital economy technologies simultaneously along the entire "front": from schoolchildren preparing to enter universities to production personnel whose professional development should be carried out taking into account the specifics of the digital transformation of production.

In order to implement end-to-end educational support for the digital production transformation, it is necessary to train personnel in a fundamentally new way, i.e. create leading school centers that at the earliest level provide young people's understanding of the entire spectrum of future interested researchers, developers, creators and consumers of new production technologies. These school centers should be formed at leading universities (university lyceums or a Pre-university), where university leading research and educational centers should also be created; the above-mentioned Consortium is capable of becoming the core of these educational transformations. Throughout the university "educational trend" (from first-year students to postgraduates), the youth should have a common task, i.e., to master new opportunities arising from end-toend digital technologies, search for and create new technological solutions or production schemes, and develop fundamentally new product lines and business models for implementing new manufacturing technologies. At large industrial complexes subject to digital transformation (digital transformation of the nuclear industry is today determined by the Unified Digital Strategy approved in November 2018), it is necessary to form industrial research and educational centers that can be created on the basis of corporate academies. In the EDT roadmaps being formed, research and educational centers should be located on the time line one above another and, in the course of development, consistently demonstrate the "flow" of trained personnel - from school to universities and from universities to production facilities. An important factor of educational training in digital transformation of the nuclear industry is postgraduate study: postgraduates, mastering digital technologies, are moving faster towards defending dissertations, forming at the same time new approaches to the implementation of scientific achievements, which can also contribute to corporate co-financing of the educational process. In general, such corporate co-financing of educational activities can give a new impetus not only to the development of unique educational programs for talented young people but also to the emergence of new approaches to financial support for sustainable economic growth based on the development of high technologies.

\section{Environmental imperative in training personnel for the emerging nuclear industry}

Electricity consumers around the world are increasingly choosing clean, renewable energy sources. People, companies, and governments of different countries are not indifferent to how the goods and services for which the consumer pays are produced. Electricity is no exception, and that is why nuclear energy, as one of the types of environmentally friendly and stable power generation will play an increasingly important role in the future. At the same time, growing competition, changes in market conditions and consumer expectations are forcing energy companies to constantly improve themselves, developing risk management systems and increasing the efficiency of applied management models.

In April 2019, participants in the ATOMEXPO-2019 forum in Sochi - heads of government agencies, large 
companies, public organizations, international experts examined global issues of developing carbon-free energy, responsible approaches to ecology and natural resources, green investments, and international partnership for sustainable development. Among the key topics of the round tables were both energy (new NPPs, the environmental effect of the development of nuclear energy, etc.) and non-energy uses of nuclear and radiation technologies in industry, science, medicine and agriculture; digital solutions for infrastructure projects; knowledge management technologies; human capital development and other areas. The personnel component in the development of the nuclear industry and the export of education were also among the main topics of the forum.

The environmental imperative is associated with the development of the bicomponent nuclear industry with thermal and fast neutron reactors with a nuclear fuel cycle closure, which can provide a fundamental solution to the problem of handling spent nuclear fuel (SNF) and radioactive waste (RW), and will also require human resourcing. However, to date, Russia has accumulated about five hundred million cubic meters of liquid and more than seventy million tons of solid radioactive waste in the presence of 1600 enterprises handling them (which requires specially trained personnel), the prospective development of which without a practical solution to the problem of radioactive and high-level waste disposal is impossible. This is especially true for nuclear energy - the recently adopted law provides for a new RW management strategy, which is based on the concept of mandatory disposal and isolation of HLW and SNF reprocessing products in geological formations to prevent migration of medium- and long-lived radionuclides in the hydrosphere so as to ensure the safety of the population and the environment. Personnel training programs for "green energy" (including the RW/SNF management) have been developed and implemented at a number of universities; the environmental imperative will be implemented by trained young people using the most modern production and environmental technologies.

\section{Personnel policy for the near future}

In all world energy forecasts, the nuclear industry occupies a significant share of the energy balance and has its own ecological niche - this is the industry of developing regions without emissions of greenhouse gases. The Rosatom State Corporation has some experience with the digital contribution to atomic technology. Given the fact that most nuclear power units are to be built abroad by 2030, a number of economic challenges arise, which are assessed in a number of works on scientific and technological forecasting:

- the increased competition from foreign (in particular, Chinese and Korean) companies;

- the need to reduce the construction time of NPPs; and
- the urgent need to reduce the cost of construction itself and achieve the cost of electricity throughout the life cycle ensuring long-term competitiveness of NPPs.

Scientific and technical assistance in solving these problems can be provided by the transition to project information modeling: effective construction management systems make it possible to control the timing, cost and quality of construction, i.e., all that concerns each customer and each contractor, especially risk assessments when forming an economic model for implementing NPP projects. However, the use of digital technologies in turn entails new challenges. New professions are emerging, the requirements for designers' competences and knowledge are increasing. New technologies entail new standards for their application. And if a certain technology has already tightly entered the life of most of the world or a group of countries, then the rest will have to adapt to them. The main nuclear competitors of Russia - China, Korea and France - have already created their international digital association, "Building Smart". They have been developing a common standard for more than five years, working in a single environment, and creating a single information platform. All this is also associated to the standards of the European Union - in many European countries information modeling has already been introduced as a prerequisite. The digital platform of the nuclear industry is a prospect of the near future, and the personnel training policy should take this into account.

Within the framework of the ATOMEXPO-2019 forum in Sochi, on April 15, 2019, the Rosatom State Corporation together with the Union of Young Professionals (WordSkills Russia) held a round table discussion on "Human capital as a factor of economic growth: from national interests to international cooperation". The discussion was attended by the leaders of the World Nuclear Association (WNA), the Union of Young Professionals (WorldSkills Russia), the Talent and Success Foundation, and a number of universities; the discussion was led by T.A. Terentyeva, HR Director of the Rosatom State Corporation. The topic of discussion was the issue of a global study of the world's best training practices in the context of current economic, technological and social changes, which are jointly conducted by the Rosatom State Corporation, BCG and Union "WorldSkills Russia". The Rosatom State Corporation is the national strategic partner of the future $45^{\text {th }}$ World Skills Championship according to WorldSkills standards, which will be held in Kazan on August 22-27, 2019. About 1600 young professionals from more than 60 countries will compete in 56 competences. More than 1,500 experts will evaluate them. The competitions will be held at the site of the Kazan Expo international exhibition center. This format - involving, developing and promoting young professionals - will become in the near future one of the cornerstones of personnel policy; NRNU MEPhI takes an active part in the movement of young professionals. 


\section{Partnership of generations - the basis of human resourcing for the long-term development of the nuclear industry}

Partnership is one of the leading values of the modern young generation. To withstand high competition for the best personnel, organizations must not only be saturated with the culture of partnership from the inside but also act as reliable partners for one another in attracting young employees. The success of the struggle of nuclear industry companies for the younger generation of specialists in the era of global digital transformation depends on this.

On April 16, 2019, in the framework of the XI International Forum "Atomexpo-2019" in Sochi, the INPO "Corporate Academy of Rosatom" held a round table on the topic "New Atomic Generation: partnership for development". Representatives of such organizations as the ITER Organization, Vienna International Center for Nuclear Expertise, Universum, Goodnight Consulting, Roland Berger, Rosatom State Corporation, leading universities and other organizations took part in the round table. They also managed to discuss career preferences of young people in Russia and the world, examples of overcoming the barriers of interaction that exist in the global nuclear industry, best practices for implementing a partnership culture when interacting with external youth audiences, as well as within organizations. The topic of partnership, succession of generations is a widely discussed issue in the university community, in particular, NIIU MEPhI supports the youth movement in educational, scientific and social formats.

A vision of the future or scientific and technological forecasting is written down today in the articles of the federal law "On strategic planning in the Russian Federation" as the main tool for managing development. A sociological analysis of development (Strikhanov and Shere- gi 2006, Strikhanov et al. 2007) confirms the priority of education in all areas of developing human activity. Such a field as nuclear energy not only has a lot of peculiar features but is also very attractive for partnerships between generations. Only professionally trained youth, replacing the older generation, is able to take this high-tech industry to a new path of growth and development.

\section{Conclusion}

The growing demand for affordable, environmentally friendly electricity creates significant long-term opportunities for the development of the nuclear industry. The depletion of fossil fuel residues, the need to reduce carbon dioxide and greenhouse gas emissions make inevitable an increase in the share of nuclear energy in the energy balance of most countries and regions. At the same time, the effective development of the industry largely depends on the response to the urgent challenges it faces, namely, unconditional security of operation of all nuclear facilities under any conditions, long-term management of radioactive waste, and management of nuclear power plants at all stages of the life cycle. It is necessary to make joint efforts of employers and the educational community to ensure the growth of the quality of professional education and reduce the gap between the qualification requirements for employees and the competences of graduates. All these aspects are taken into account in the training programs currently being developed for the nuclear industry, including the international component, which is clearly illustrated by the creation of a branch of our university in the Republic of Uzbekistan. The improvement of existing and the development of new innovative technologies is a prerequisite for the development of a nuclear energy system that meets the principles of safety and sustainable development. All solutions to these problems are in the hands of the young people who are being trained throughout the country.

\section{References}

- Ilyina NA, Putilov AV (2012) Analysis of formation, current state and prospects of development of the main participants of the world innovative Nuclear market. Innovatsii [Innovations] 9: 10-15. [in Russian]

- Ivanov VV, Putilov AV (2017) Digital Future: The next step in the development of nuclear energy technologies. Energeticheskaya Politika [Energy Policy] 3: 31-42. [in Russian]

- Kirillov PL (2018) Alexandr Illich Leipunsky and his principles in the system of higher Education. Izvestia vuzov. Yadernaya Energetika [News of Higher Educational Institutions. Nuclear Energy] 1: 165-168. [in Russian]

- Putilov AV, Vorobyev AG, Strikhanov MN (2010) Innovation activity in the nuclear industry. Book one. "Basic principles of innovation policy”. Ruda i metally, Moscow, 184 pp. [in Russian]

- Strikhanov MN, Sheregi FE (2006) Science in Russia. Sociological analysis. Center for Social Forecasting Publ., Moscow, 455 pp. [in Russian]

- Strikhanov MN, Trubetzkov DI, Koroovsky AA, Sharaevsky YuP, Khramov AE (2007) Higher school of Russia from the position of nonlinear dynamics (problems, estimations, models). Fizmatlit Publ., Moscow, 192 pp. [in Russian] 